\title{
GMR
}

\section{Genetic diversity and structure of native and non-native populations of the endangered plant Pinus dabeshanensis}

\author{
Z.Y. Zhang ${ }^{1,2}$, H. Wang ${ }^{2}$, W. Chen ${ }^{2}$, X.M. Pang ${ }^{2}$ and Y.Y. Li ${ }^{2}$ \\ ${ }^{1}$ Beijing Key Laboratory of Ornamental Plants Germplasm Innovation \& \\ Molecular Breeding, National Engineering Research Center for Floriculture, \\ Beijing Laboratory of Urban and Rural Ecological Environment, \\ College of Landscape Architecture, Beijing Forestry University, Beijing, China \\ ${ }^{2}$ National Engineering Laboratory for Tree Breeding, \\ College of Biological Sciences and Technology, Beijing Forestry University, \\ Beijing, China \\ Corresponding author: Y.Y. Li \\ E-mail: yingyueli@bjfu.edu.cn
}

Genet. Mol. Res. 15 (2): gmr.15027937

Received October 28, 2015

Accepted January 29, 2016

Published June 10, 2016

DOI http://dx.doi.org/10.4238/gmr.15027937

\begin{abstract}
Owing to a severe decline in its abundance, Pinus dabeshanensis has been listed as an endangered species by the International Union for the Conservation of Nature. Although several restoration events have been undertaken since the 1960s, the natural population genetic structure of this species remains to be investigated. Herein, we examined the level of genetic diversity and structure of two native and two non-native populations using 10 microsatellite loci. A relatively high level of genetic variation $\left(H_{\mathrm{O}}=0.586 \pm 0.039\right)$ and a low level of population differentiation $\left(F_{\mathrm{ST}}=0.016 \pm 0.011\right)$ were revealed. For forensic investigation, an assignment test was performed. To better understand the genetic differentiation between the native and nonnative populations, the individuals in the transplanted and cultivated populations may have derived from populations that were not surveyed
\end{abstract}


in this study. In light of our results, we discuss the real problems faced by all four populations and provide useful information for management decision-making.

Key words: Pinus dabeshanensis; Translocations; Cultivated population; Assignment test; Conservation genetics

\section{INTRODUCTION}

Pinus dabeshanensis W.C. Cheng \& Y.W. Law is an endangered five needle pine endemic to the southern end of the Dabie Mountains (Anhui Province, China). The population of $P$. dabeshanensis has undergone a dramatic decline during the past century, and wild individuals are now restricted to Jinzhai (Anhui), Yuexi (Anhui), and Yingshan (Hubei) counties. Owing to the precarious condition of this species, P. dabeshanensis was listed as endangered by the International Union for Conservation of Nature (IUCN) in 1998 and was afforded second class state protection by the Chinese Red Data Book in 1992 (Fu, 1992).

Many in situ conservation management programs have been implemented under the advocacy of the National Forestry Bureau of China since 1981. Most native habitats have been protected as natural reserves, and many wild adult trees were labeled. Meanwhile, ex situ protection and restoration programs have been initiated. Ex situ collection is a key conservation method, and it offers many endangered and threatened plants an important insurance policy for the future (Brundrett et al., 2003). From 1978 to 1991, several translocation events took place, and hundreds of seedlings and adolescents were transplanted from wild habitats to bare ground. After acclimation that lasted many decades, a new, non-native population was established in the Wenao Reserve near the species' original distribution. What is more, seed collection from wild adult trees among the remnant populations was performed during the harvest years. Seedlings from this effort were artificially cultivated in a nursery for five years and then transplanted to fertile bare ground, thus establishing a new population in the Miaodaoshan Reserve.

Whether these efforts are necessary or effective is still open to debate because information about the levels of genetic diversity within and among the extant populations of $P$. dabeshanensis is lacking. Understanding the genetic history and variation in natural populations is essential for developing rational in situ conservation strategies and managing ex situ germplasm collections (Swarts et al., 2009; Lauterbach et al., 2011; Liu et al., 2013).

To assess genetic variation, microsatellites (simple sequence repeats, SSRs) are ideal owing to their high levels of polymorphism, co-dominance, reproducibility, and transferability. SSRs, and especially expressed sequence tag-SSRS (EST-SSRs), have been widely used in studies of conservation genetics of endangered species, including Annamocarya sinensis (Zhang et al., 2013), Toona ciliata (Liu et al., 2014), Aconitum austrokoreense (Yun et al., 2015), and others. Regarding P. dabeshanensis, Zhang et al. (2015) developed 28 polymorphic SSR markers from the transcriptome assembly of the congeneric species P. lambertiana, whereas Xiang et al. (2015) identified 19 polymorphic EST-SSRs from a cDNA library of $P$. dabeshanensis needles. However, the natural pattern of genetic diversity of $P$. dabeshanensis is still unexplored.

In this study, we propose to address the following questions: 1) what is the genetic diversity and spatial structure of the remnant wild populations? and 2) does the new transplanted population and cultivated population contain sufficient genetic variation? By answering these questions, we seek to reveal the genetic affinity and differentiation between native and non- 
native populations of $P$. dabeshanensis, and to provide significant information to develop feasible strategies for the conservation of this endangered species.

\section{MATERIAL AND METHODS}

\section{Study area and field sampling}

A field survey was conducted among all extant $P$. dabeshanensis populations from April to July 2012. Eighty-four wild-occurring plants were identified, and 64 samples were collected. Two adult individuals $(\mathrm{DBH}>30 \mathrm{~cm})$ were found in Yaluoping Reserve $\left(30^{\circ} 58.592 \mathrm{~N}\right.$, $\left.116^{\circ} 02.811^{\prime} \mathrm{E}\right)$, but excessive height prevented collection of fresh needles. Eleven individuals, including four adults and seven juveniles, were found in Kangwangzhai Reserve $\left(31^{\circ} 39.510^{\prime} \mathrm{N}\right.$, $115^{\circ} 39.240^{\prime} \mathrm{E}$ ), but none were sampled due to their location on the edge of a cliff that made them impossible to reach. In Wenao Reserve $\left(30^{\circ} 49.259^{\prime} \mathrm{N}, 116^{\circ} 06.541^{\prime} \mathrm{E}\right), 71$ plants were identified and 64 samples were collected. Of the seven trees that were not sampled in Wenao Reserve, needle collection was deemed detrimental to the survival of four seedlings whereas the height of three adult trees precluded access to fresh needles.

The 64 native samples were classified into two populations (Pop 1 and Pop 2) because the two territories are separated by several mountains and $>20 \mathrm{~km}$. An additional 94 samples were obtained from two non-native populations (Pop 3 and Pop 4). Pop 3 was established by transplanting wild seedlings to bare ground in Wenao Reserve, whereas Pop 4was a cultivated population established by an artificial seed-collection program in Miaodaoshan Reserve (Table 1 and Figure 1).

Table 1. Locations of native Pinus dabeshanensis populations used in this study.

\begin{tabular}{l|l|c|c|c}
\hline Population code & Sampling locations & Latitude (N) & Longitude (E) & Sample size \\
\hline Pop 1 & Wenao, Anhui & $30^{\circ} 49.252^{\prime}$ & $116^{\circ} 06.579^{\prime}$ & 31 \\
\hline Pop 2 & Dawanggou, Anhui & $30^{\circ} 52.235^{\prime}$ & $116^{\circ} 08.358^{\prime}$ & 33 \\
\hline Pop 3 & Wenao Reserve, Anhui & $30^{\circ} 49.082^{\prime}$ & $116^{\circ} 07.180^{\prime}$ & 31 \\
\hline Pop 4 & Miaodaoshan Reserve, Anhui & $30^{\circ} 47.526^{\prime}$ & $116^{\circ} 06.324^{\prime}$ & 63 \\
\hline
\end{tabular}

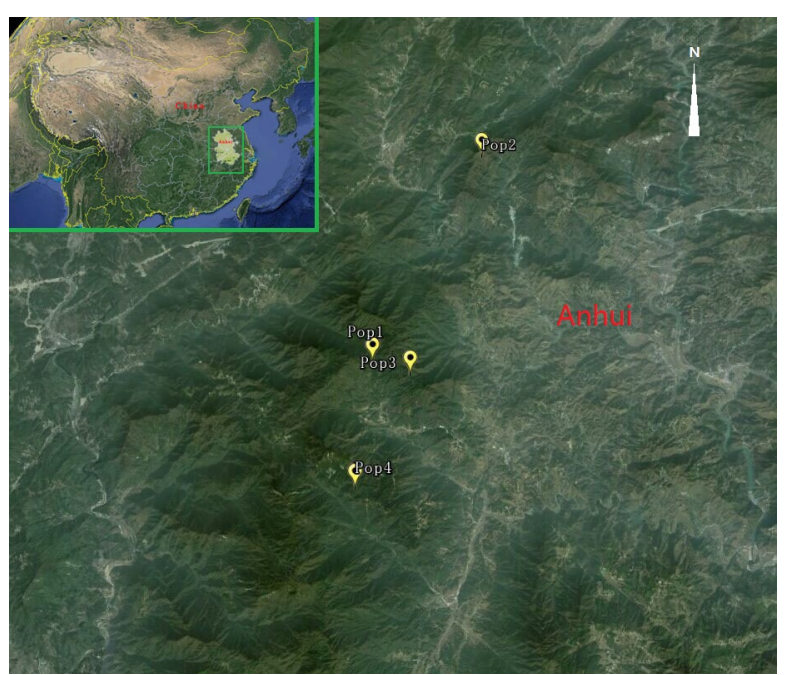

Figure 1. Geographic locations of the four sample populations. 


\section{DNA extraction and microsatellite genotyping}

DNA extraction was performed using fresh leaves and a modified $2 \mathrm{X}$ cetyltrimethylammonium bromide protocol (Doyle, 1987) and DNA quality was verified using spectrophotometry. Microsatellite markers were selected from Zhang et al. (2015) for relatively high levels of heterozygosity, broad allelic range and PIC values. Finally, 10 SSR markers (BJFU-PL-439, BJFU-PL-93, BJFU-PL-340, BJFU-PL-594, BJFU-PL-617, BJFU-PL-150, BJFU-PL-414, BJFU-PL-443, BJFU-PL-524 and BJFU-PL-243) were used to genotype all samples. Polymerase chain reaction (PCR) amplifications were performed as described by Zhang et al. (2015). PCR products were resolved using the ABI 3730XL DNA Analyzer (Genewiz Biotechnology Co., Ltd., Beijing, China), and data were analyzed using Gene-Marker software (SoftGenetics LLC, State College, PA, USA).

\section{Data analysis}

\section{Genetic diversity}

The estimated parameters of genetic diversity comprised the number of alleles $\left(N_{\mathrm{A}}\right)$, effective number of alleles $\left(N_{\mathrm{E}}\right)$, observed $\left(H_{\mathrm{O}}\right)$ and expected $\left(H_{\mathrm{E}}\right)$ heterozygosity and inbreeding coefficients $\left(F_{\text {IS }}\right)$ and were assessed using GeneAlEx 6.2 (Peakall and Smouse, 2006). Hardy-Weinberg equilibrium at each locus for each population and LD were examined using Genepop v. 4.0 (Raymond and Rousset, 1995; Rousset, 1997).

\section{Population structure}

To assess spatial genetic structure, we used principal coordinate analysis (PCoA) and a clustering method based on Bayesian models. PCoA was performed based on genetic distances using GeneAlex 6.2 (Peakall and Smouse, 2006). As an alternative approach, we used a Bayesian analysis implemented in STRUCTURE (Pritchard et al., 2000) to examine the number of differentiated populations with $\mathrm{K}$ set from 2-8, with each $\mathrm{K}$ estimate replicated 10 times with a 100,000 burn-in period and 100,000 Markov chain Monte Carlo iterations. The optimum number of clusters was determined by combining the recommendations of Pritchard et al. (2000) and the approach of Evanno et al. (2005) by uploading results to Structure Harvester (http://taylor0.biology.ucla.edu/structureHarvester/) (Earl and vonHoldt, 2012).

\section{Bottleneck}

In this study, we detected recent population bottlenecks using the Wilcoxon sign-rank test in BOTTLENECK 1.2.02 (Piry et al., 1999). We used only the Wilcoxon's test, which is considered the most appropriate and most powerful for analysis of fewer than 20 loci (Piry et al., 1999). If a population decline occurred relatively recently, the mutation-drift equilibrium would be disrupted because the loss of alleles occurred more quickly than the reduction in heterozygosity (Luikart and Cornuet, 1998; Piry et al., 1999). These analyses were conducted using the stepwise mutation model (SMM), the infinite allele model (IAM) and the two phase model (TPM). For the TPM, $70 \%$ of the mutations were assumed to occur under SMM and 30\% under IAM. A mode-shift away from an L-shaped distribution of allelic frequencies was also used. 


\section{Assignment test}

To infer the possible origin of the non-native populations of $P$. dabeshanensis, an individual assignment test was performed using a Bayesian multilocus approach (Rannala and Mountain, 1997) implemented in GeneClass2 (Piry et al., 2004). In the Bayesian modelbased assignment test, the exclusion simulation method did not require the assumption that the true population of origin had been sampled (Paetkau et al., 2004). In this study, the reference populations were Pop 1 and Pop 2, and the samples to be assigned were all individuals in Pop 3 and Pop 4. We performed this assignment test using the criteria of Rannala and Mountain (1997), including the 'leave one out' procedure, which calculates the probability that an individual's multilocus genotype occurs in each reference population. After we identified the population with highest probability, we evaluated rejection and acceptance of membership of the genotype to the population by the Monte Carlo resampling method of Paetkau et al. (2004). The probability of the given individual multilocus genotype was compared with the distribution of probabilities of multilocus genotypes (10,000 replicates) generated based on the allele frequencies of the population. If the value was below $0.05(\alpha<0.05)$, the individual was excluded from the given population.

\section{RESULTS}

\section{Genetic diversity}

Two (BJFU-PL-439 and BJFU-PL-443) to 14 (JFU-PL-617) unique alleles per microsatellite locus were identified for 54 alleles identified among all 10 loci in the 158 samples surveyed. The number of effective alleles $\left(N_{E}\right)$ per population was $1.731,1.703,1.863$ and 1.685, and the richness of alleles $\left(A_{R}\right)$ was $3.5803,3.4526,3.7838$ and 3.2887 for Pop 1, Pop 2, Pop 3 and Pop 4, respectively. The numbers of private alleles and rare alleles $\left(A_{P} / R\right)$ were 3/13, 2/14, 4/15 and 5/13 for Pop 1, Pop 2, Pop 3 and Pop 4, respectively (Table 2).

\section{Table 2. Population genetics estimates for four Pinus dabeshanensis populations.}

\begin{tabular}{l|c|c|c|c|c|c|c|c}
\hline Pop & $N_{\mathrm{A}}$ & $N_{\mathrm{E}}$ & $I$ & $A R$ & $H_{\mathrm{O}}$ & $H_{\mathrm{E}}$ & $F_{\mathrm{IS}}$ & $A_{P} / R$ \\
\hline Pop1 & 3.600 & 1.731 & 0.655 & 3.580 & 0.456 & 0.349 & -0.292 & $3 / 13$ \\
\hline Pop2 & 3.500 & 1.703 & 0.633 & 3.453 & 0.464 & 0.349 & -0.317 & $2 / 14$ \\
\hline Pop3 & 3.800 & 1.863 & 0.734 & 3.784 & 0.502 & 0.398 & -0.246 & $4 / 15$ \\
\hline Pop4 & 3.900 & 1.685 & 0.627 & 3.289 & 0.419 & 0.343 & -0.214 & $5 / 13$ \\
\hline Total & 3.700 & 1.745 & 0.662 & - & 0.460 & 0.360 & - & $14 / 55$ \\
\hline Mean & 0.266 & 0.100 & 0.057 & - & 0.052 & 0.032 & - & - \\
\hline
\end{tabular}

$N_{\mathrm{A}}$ : observed allele number; $N_{\mathrm{E}}$ : effective allele number; $I$ : Shannon's information index; $A R$ : allelic richness; $H_{\mathrm{O}}$ : observed heterozygosity; $H_{\mathrm{E}}$ : expected heterozygosity; $F_{I S}$ : fixation index in subpopulations; $A P$ : number of private alleles; $R$ number of rare alleles (here defined as alleles with a frequency of less than $5 \%$ ).

The average observed $\left(H_{\mathrm{O}}\right)$ and expected $\left(H_{\mathrm{E}}\right)$ heterozygosities were 0.460 and 0.360 , and ranged from 0.419 to 0.502 and from 0.343 to 0.398 , respectively (Table 2). As expected, the heterozygosity values in wild populations (Pop 1 and Pop 2) were slightly lower than those in the ex situ conservation population (Pop 3), but slightly higher than those in the artificially cultivated population (Pop 4). The test for Hardy-Weinberg equilibrium found that, of 40 locus-population combinations, 1,4 , and 10 showed significant deviation at $\mathrm{P}<0.05,0.01$, and 
0.001 , respectively. We did not find evidence of $L D$ among any pairs of loci with the exception of observed LD between BJFU-PL-93 and BJFU-PL-150. The values of the inbreeding coefficient $\left(F_{\text {IS }}\right)$ over all populations for each locus ranged from -0.811 (BJFU-PL-340) to 0.365 (BJFU-PL-439), with the mean of -0.186 (data not shown). This value was similar in all populations at all loci. Inbreeding coefficients by population were, from relatively highest to relatively lowest, Pop 4 (-0.214), Pop 3 (-0.246), Pop 1 (-0.292) and Pop 2 (-0.317) (Table 2).

\section{Population structure}

Weak genetic differentiation was found among populations. Analysis of molecular variance (AMOVA) showed that $91 \%$ of variation occurred within populations and $9 \%$ among populations (data not shown). Low genetic differentiation $\left(F_{\mathrm{ST}}\right)$ values and high gene flow $(\mathrm{Nm})$ were consistent with the AMOVA results. The highest $F_{\mathrm{ST}}$ value was only 0.028 and was observed between Pop 3 and Pop 4, whereas the lowest was 0.011 and was observed between Pop 1 and Pop 2 (data not shown). The lowest $\mathrm{Nm}$ value observed was 8.630 between Pop 3 and Pop 4,whereas the highest, between Pop 1 and Pop 2, was 22.449 (data not shown). The mean $\mathrm{Nm}$ value for SSR markers was 16.821 with a range ranging from 83.182 (BJFUPL-340) to 2.136 (BJFU-PL-93).

Recent bottlenecks under three mutational models and the allele frequency distribution test (mode-shift) were detected in all populations. No significant signature of a recent bottleneck was found under IAM or SMM, except in Pop 1 with borderline significance $(\mathrm{P}=0.3223)$. However, only Pop 2 did not show a significant signature $(\mathrm{P}=0.08393)$ under the TPM model, which was apparently the most appropriate mutational model for microsatellite markers. The allele frequency distribution test did not detect any signature of a recent bottleneck in any population (Table 3).

Table 3. Probabilities from Wilcoxon sign-rank tests for heterozygosity excess and mode shift using BOTTLENECK.

\begin{tabular}{l|c|c|c|c}
\hline Population & IAM & SMM & TPM & Mode shift \\
\hline Pop 1 & 0.62500 & $0.03223^{*}$ & $0.00195^{* *}$ & Normal \\
\hline Pop 2 & 0.76953 & 0.32227 & 0.08398 & Normal \\
\hline Pop 3 & 0.84570 & 0.19336 & $0.00977^{* *}$ & Normal \\
\hline Pop 4 & 0.73438 & 0.20313 & $0.02734^{*}$ & Normal \\
\hline
\end{tabular}

IAM = infinite allele model; SMM = stepwise mutation model; TPM = two-phase model; Model shift $=$ shifted distribution of allele frequencies. *Significant at $\mathrm{P}<0.05$. **Significant at $\mathrm{P}<0.01$.

Analyses using STRUCTURE HARVESTER suggested that the optimal K was 2 [mean $\ln \mathrm{P}(\mathrm{K})=-2,223.57$ ] (Figures 2 and 3). Analyses of the wild dataset, excluding the cultivated Pop 4 samples, suggested a further $K=2$ clusters [mean $\ln P(K)=-862.51$ ], with no clear pattern of isolation (data not shown). The results were also congruent with the PCoA plot of the four populations in which the first axis accounted for $44.50 \%$ of the total variation. Pop 4 was separated from Pop 1, Pop 2 and Pop 3 by the second axis, which accounted for 39.73\% of the total variation (data not shown).

\section{Assignment test}

Using all 10 loci and the two native populations as reference data, the self-assignment test indicated that 14 individuals (15\% of the total in Pop 3 and Pop 4), including six in 
Pop 3 and eight in Pop 4, were assigned correctly. The remaining 80 (85\%) individuals were unassigned, and none were considered immigrants. Interestingly, all 14 individuals were assigned to Pop 2 as the probable population of origin (data not shown). Considering the low $F_{\mathrm{ST}}$ between Pop 1 and Pop 2 and the results from STRUCTURE, the procedure was performed again considering all 64 wild individuals as one probable origin population as the reference datum. Only two, both in Pop 4, were assigned correctly, and none were immigrants.

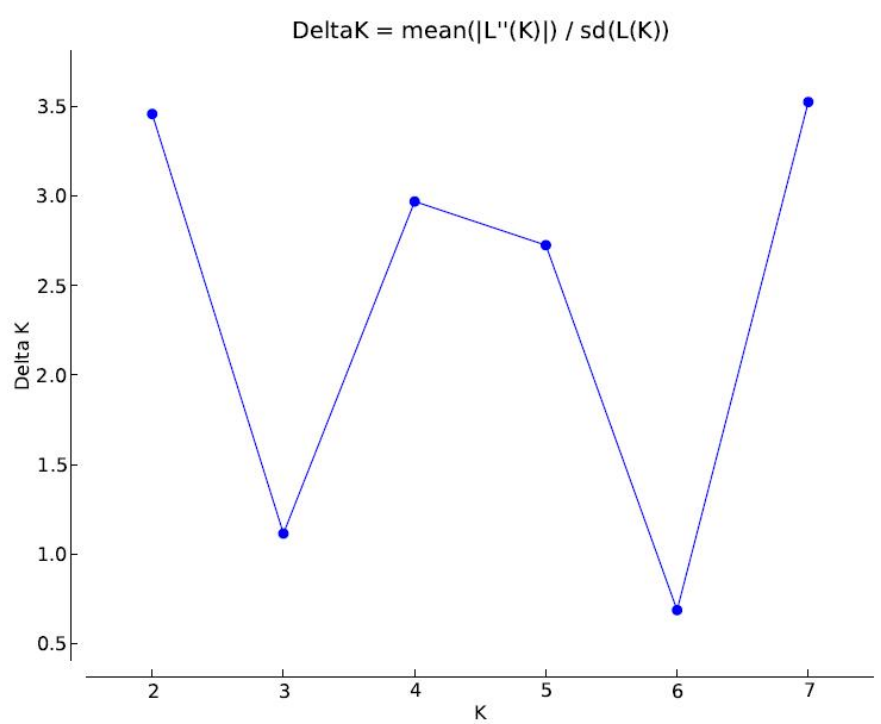

Figure 2. Identification of optimal K with STRUCTURE HARVESTER. In the four populations used in the study, there was a peak in $K=2$, indicating that the population was possibly composed of two sub-clusters.

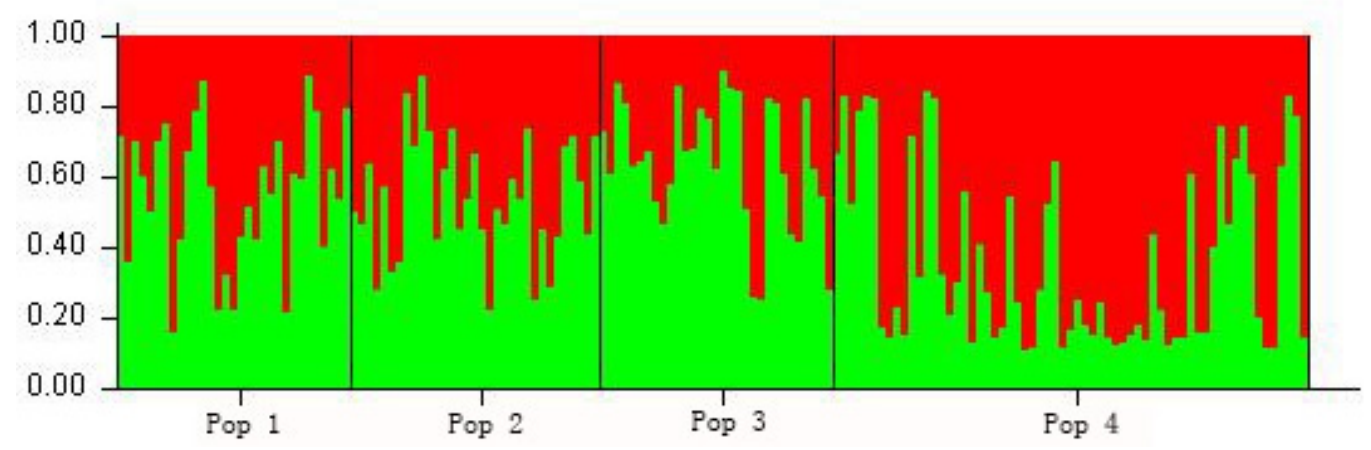

Figure 3. Population structure of four populations of Pinus dabeshanensis estimated by STRUCTURE at K $=2$. Thin vertical lines represent individuals.

\section{DISCUSSION}

\section{Genetic diversity}

With a mean $H_{\mathrm{O}}$ of 0.46 and $A_{\mathrm{R}}$ of 3.53 , the endangered $P$. dabeshanensis had a 
relatively high genetic diversity. When considering only the wild individuals, excluding the artificially cultivated population, these indicators increased to 0.48 and 3.61, respectively. Interestingly, almost all parameters indicated that Pop 3 had the highest genetic variation and Pop 4 the lowest. As noted above, Pop 3 is a transplanted population with varying origins and that may include an area that is larger than the current wild distribution. Notably, however, even though the genetic diversity of Pop 4 was lower than those of the three wild populations, these values were not significant, and some genetic parameters were even higher (such as the highest five private alleles). This relatively high level of heterozygosity in ex situ populations could be due to high founder size or high effective population size in the past. Our results, with average $H_{\mathrm{E}}=0.360$, were lower than those reported for some conifer species including P. cembra (average $H_{\mathrm{E}}=0.537$; Dzialuk et al., 2014), P. massoniana $\left(H_{\mathrm{E}}=0.536\right.$; Bai et al., 2014), P. taeda $\left(H_{\mathrm{E}}=0.659\right.$; Al-Rabab'ah and Williams, 2002). However, it was higher than those of other studies based on SSRs including tree species P. sylvestris $\left(H_{\mathrm{E}}=0.2605\right.$; Labra et al., 2006), P. resinosa $\left(H_{\mathrm{E}}=0.358\right.$; Boys et al., 2005) and P. squamaia $\left(H_{\mathrm{E}}=0.356\right.$; Mao et al., 2015). Our results were not consistent with those of Lauterbach et al. (2012) who reported lower genetic variation in ex situ populations than in in situ populations of the endangered Silene otitis.

The negative inbreeding index and high historical gene flow support the hypothesis that P. dabeshanensis once had a large continuous distribution, an observation that is consistent with our other results. This hypothesis is also consistent with the species' recent history (personal communication with administrators of Wenao Reserve) and is further strengthened by the existence of residual or remnant tree stumps (field observation by us). Wild populations of $P$. dabeshanensis have experienced a drastic and extended decline in numbers due to devastation and deforestation over the past century. All these results indicate that $P$. dabeshanensis is under threat and has suffered a loss of genetic diversity resulting from a demographic decline.

\section{Population structure}

As the Wilcoxon test and L-shaped distribution suggested, we cannot convincingly conclude that all wild populations of $P$. dabeshanensis have undergone a recent bottleneck. It is likely that Pop 1 underwent a recent bottleneck whereas Pop 2 and Pop 3 did not. The allele richness, private alleles and rare alleles complicate the situation because once a bottleneck occurs, private and rare alleles decrease quickly (Luikart and Cornuet, 1998). Even though we believe that we sampled nearly all wild individuals and that population sizes were acceptable, this result should be viewed with caution because we examined a modest number of individuals with 10 microsatellite loci.

Our results revealed weak genetic structure. AMOVA analysis showed 91\% intrapopulation and $9 \%$ inter-population genetic variation. The structure analysis using the Bayesian algorithm allowed us to group the two natural wild populations as one and the non-native wild population as a mixed ancestry. Since STRUCTURE could not perform analysis on $\mathrm{K}=1$, the result of $\mathrm{K}=2$ is unconvincing and debatable, especially considering the $9 \%$ amongpopulation variance and the low $F_{\mathrm{ST}}$ among populations. This issue can be better explored when some breeding and genetic background becomes available.

The assignment test and forensic analysis used to determine possible origins of unknown individuals have been applied successfully in many plant species (Lowe et al., 2010; Jolivet and Degen, 2012; Degen et al., 2013; Zheng et al., 2015). Honjo et al. (2008) 
reported an assignment analysis of the geographic origins of cultivars of the endangered species Primula sieboldii, and Nazareno and Dos Reis (2014) successfully identified the origins of an illegally traded population of Butia eriospatha. The innovation of our study is that we traced the geographic origin of all samples from both a transplanted population and an artificially cultivated population. However, Cornuet et al. (1999) pointed out that the accuracy of assignment tests increases with increasing genetic differentiation among populations. In this study, the genetic differentiation between the two wild referenced populations was found to be very low $\left(F_{\mathrm{ST}}=0.011\right)$. As such, an assignment test between the two populations is difficult and the results should be viewed with caution.

\section{Implications for conservation}

From a conservation perspective, an appropriate strategy would sustain current genetic diversity and ensure the long-term evolution of an endangered species (Forest et al., 2007). In terms of $P$. dabeshanensis, the genetic variation that exists in both wild populations and non-native settings should be preserved. Meanwhile, increased artificially cultivated populations established by transplantation and seed collection should be developed as an effective complementary measure.

Planning for both population and landscape conservation should first focus on the protection of native wild populations, which cannot be recovered. The two native wild populations of $P$. dabeshanensis contain a substantial portion of the species' remaining genetic diversity, regardless of population size. Thus, priority should be given to these regions to avoid further population decline. Unfortunately, most of these individuals are found on unprotected land and belong to different landowners. Therefore, instruction and engagement of landowners play an important role in the future protection of the species.

Between-site transplantation and reintroduction may also play important roles in recovering threatened populations. Pop 3 in this study is a representative example. According to the field survey, these transferred individuals are healthy in the novel environment, and some are mature and reproductive. What its impact is on the native population is a question worthy of attention. Between-site transplantations could lead to outbreeding depression and reduced fitness through disruption of co-adapted gene complexes or local adaptations. Meanwhile, outbred individuals with lower fitness would have a lower chance of survival to the reproduction stage than those remaining in extant populations. To address this issue, further research should concentrate on breeding system studies. Comparison of Pop 3 and Pop 4 will provide insight into maintaining genetic diversity in transplantation between sites. The best way to maintain genetic diversity is to establish a new population from as many extant populations as possible. However, this may be unfeasible, because only four native seedlings were found among the entire distribution. Based on this situation, artificially cultivated populations established by seed collection are more feasible for P. dabeshanensis. However, the small number of plants contributing to the next generation is a limiting factor when this method is used, and genetic diversity in subsequent generations will be increased when seeds are collected from a greater number of reproductive plants. Including the number of reproductive plants in Pop 3 from which seeds are collected would help improve diversity.

To our knowledge, this is the first genetic analysis conducted of $P$. dabeshanensis. Management efforts including transplantation and reintroduction can play a key role in recovering this threatened species. An optimal scenario would include the effective protection 
of most native individuals, and would encourage increased genetic variance in transplanted and reintroduced populations. Future research should concentrate on breeding system studies to identify the best management practices for the long-term persistence of this species.

\section{Conflict of interest}

The authors declare no conflict of interest.

\section{ACKNOWLEDGMENTS}

The authors are grateful to the anonymous reviewers for their constructive comments. Research supported by grants from the "National Natural Science Foundation of China (Grant \#31400578)" and "Beijing Higher Education Young Elite Teacher Project (Grant \#YETP0756)", and the "Project of the Field Ambulance and Breeding of Rare and Endangered Species (\#2012-LYSJWT-12)" of the State Forestry Administration.

\section{REFERENCES}

Al-Rabab'ah MA and Williams C (2002). Population dynamics of Pinus taeda L. based on nuclear microsatellites. For. Ecol. Manage. 163: 263-271. http://dx.doi.org/10.1016/S0378-1127(01)00584-9

Bai TD, Xu LA, Xu M and Wang ZR (2014). Characterization of masson pine (Pinus massoniana Lamb.) microsatellite DNA by 454 genome shotgun sequencing. Tree Genet. Genomes 10: 429-437. http://dx.doi.org/10.1007/s11295-013-0684-y

Boys J, Cherry M and Dayanandan S (2005). Microsatellite analysis reveals genetically distinct populations of red pine (Pinus resinosa, Pinaceae). Am. J. Bot. 92: 833-841. http://dx.doi.org/10.3732/ajb.92.5.833

Brundrett MC, Scade A, Batty AL, Dixon KW, et al. (2003). Development of in situ and ex situ seed baiting techniques to detect mycorrhizal fungi from terrestrial orchid habitats. Mycol. Res. 107: 1210-1220. http://dx.doi.org/10.1017/ $\underline{\mathrm{S} 0953756203008463}$

Cornuet JM, Piry S, Luikart G, Estoup A, et al. (1999). New methods employing multilocus genotypes to select or exclude populations as origins of individuals. Genetics 153: 1989-2000.

Degen B, Ward SE, Lemes MR, Navarro C, et al. (2013). Verifying the geographic origin of mahogany (Swietenia macrophylla King) with DNA-fingerprints. Forensic Sci. Int. Genet. 7: 55-62. http://dx.doi.org/10.1016/j. fsigen.2012.06.003

Doyle JJ (1987). A rapid DNA isolation procedure for small quantities of fresh leaf tissue. Phytochem. Bull. 19: 11-15.

Dzialuk A, Chybicki I, Gout R, Mączka T, et al. (2014). No reduction in genetic diversity of Swiss stone pine (Pinus cembra L.) in Tatra Mountains despite high fragmentation and small population size. Conserv. Genet. 15: 1433-1445. http://dx.doi.org/10.1007/s10592-014-0628-6

Earl DA and vonHoldt BM (2012). STRUCTURE HARVESTER: a website and program for visualizing STRUCTURE output and implementing the Evanno method. Conserv. Genet. Resour. 4: 359-361. http://dx.doi.org/10.1007/ $\underline{\mathrm{s} 12686-011-9548-7}$

Evanno G, Regnaut S and Goudet J (2005). Detecting the number of clusters of individuals using the software STRUCTURE: a simulation study. Mol. Ecol. 14: 2611-2620. http://dx.doi.org/10.1111/j.1365-294X.2005.02553.x

Forest F, Grenyer R, Rouget M, Davies TJ, et al. (2007). Preserving the evolutionary potential of floras in biodiversity hotspots. Nature 445: 757-760. http://dx.doi.org/10.1038/nature05587

Fu GL (1992). Chinese Red Data Book. Beijing Science and Technology Press, Beijing.

Honjo M, Ueno S, Tsumura Y, Handa T, et al. (2008). Tracing the origins of stocks of the endangered species Primula sieboldii using nuclear microsatellites and chloroplast DNA. Conserv. Genet. 9: 1139-1147. http://dx.doi.org/10.1007/ $\underline{\mathrm{s} 10592-007-9427-7}$

Jolivet C and Degen B (2012). Use of DNA fingerprints to control the origin of sapelli timber (Entandrophragma cylindricum) at the forest concession level in Cameroon. Forensic Sci. Int. Genet. 6: 487-493. http://dx.doi. org/10.1016/j.fsigen.2011.11.002

Labra M, Grassi F, Sgorbati S and Ferrari C (2006). Distribution of genetic variability in southern populations of 
Scots pine (Pinus sylvestris L.) from the Alps to the Apennines. Flora 201: 468-476. http://dx.doi.org/10.1016/j. flora.2005.10.004

Lauterbach D, Burkart M and Gemeinholzer B (2012). Rapid genetic differentiation between ex situ and their in situ source populations: an example of the endangered Silene otites (Caryophyllaceae). Bot. J. Linn. Soc. 168: 64-75. http:// dx.doi.org/10.1111/j.1095-8339.2011.01185.x

Lauterbach D, Ristow M and Gemeinholzer B (2011). Genetic population structure, fitness variation and the importance of population history in remnant populations of the endangered plant Silene chlorantha (Willd.) Ehrh. (Caryophyllaceae). Plant Biol (Stuttg) 13: 667-677. http://dx.doi.org/10.1111/j.1438-8677.2010.00418.x

Liu J, Jiang JM and Chen YT (2014). Genetic diversity of central and peripheral populations of Toona ciliata var. pubescens, an endangered tree species endemic to China. Genet. Mol. Res. 13: 4579-4590. http://dx.doi.org/10.4238/2014.June.17.10

Liu J, Sun HG, Jiang JM, Shao WH, et al. (2013). Genetic diversity of natural populations of Machilus thunbergii, an endangered tree species in eastern China, determined with ISSR analysis. Genet. Mol. Res. 12: 3689-3697. http:// dx.doi.org/10.4238/2013.March.11.10

Lowe AJ, Wong KN, Tiong YS, Iyerh S, et al. (2010). A DNA method to verify the integrity of timber supply chains; confirming the legal sourcing of merbau timber from logging concession to sawmill. Silvae Genet. 59: 263-268.

Luikart G and Cornuet JM (1998). Empirical evaluation of a test for identifying recently bottlenecked populations from allele frequency data. Conserv. Biol. 12: 228-237. http://dx.doi.org/10.1046/j.1523-1739.1998.96388.x

Mao JF, Cui BB, Zhang ZY, Liu H, et al. (2015). Development of 36 novel polymorphic microsatellites for the critically endangered tree Pinus squamaia, by transcriptome database mining. Conserv. Genet. Resour. 7: 93-94. http://dx.doi. org $/ 10.1007 / \mathrm{s} 12686-014-0300-\mathrm{y}$

Nazareno AG and Dos Reis MS (2014). Where did they come from? Genetic diversity and forensic investigation of the threatened palm species Butia eriospatha. Conserv. Genet. 15: 441-452. http://dx.doi.org/10.1007/s10592-013-0552-1

Paetkau D, Slade R, Burden M and Estoup A (2004). Genetic assignment methods for the direct, real-time estimation of migration rate: a simulation-based exploration of accuracy and power. Mol. Ecol. 13: 55-65. http://dx.doi. org/10.1046/j.1365-294X.2004.02008.X

Peakall R and Smouse PE (2006). GENALEX 6: genetic analysis in Excel. Population genetic software for teaching and research. Mol. Ecol. Notes 6: 288-295. http://dx.doi.org/10.1111/j.1471-8286.2005.01155.x

Piry S, Alapetite A, Cornuet JM, Paetkau D, et al. (2004). GENECLASS2: a software for genetic assignment and firstgeneration migrant detection. J. Hered. 95: 536-539. http://dx.doi.org/10.1093/ihered/esh074

Piry S, Luikart G and Cornuet JM (1999). BOTTLENECK: a program for detecting recent effective population size reductions from allele data frequencies. Available at http://www1.montpellier.inra.fr/CBGP/software/Bottleneck/bottleneck.html.

Pritchard JK, Stephens M and Donnelly P (2000). Inference of population structure using multilocus genotype data. Genetics 155: 945-959.

Rannala B and Mountain JL (1997). Detecting immigration by using multilocus genotypes. Proc. Natl. Acad. Sci. USA 94: 9197-9201. http://dx.doi.org/10.1073/pnas.94.17.9197

Raymond M and Rousset F (1995). GENEPOP (VERSION-1.2): Population genetics software for exact tests and ecumuncism. J. Hered. 86: 248-249.

Rousset F (1997). Genetic differentiation and estimation of gene flow from F-statistics under isolation by distance. Genetics 145: 1219-1228.

Swarts ND, Sinclair EA, Krauss SL and Dixon KW (2009). Genetic diversity in fragmented populations of the critically endangered spider orchid Caladenia huegelii: implications for conservation. Conserv. Genet. 10: 1199-1208. http:// dx.doi.org/10.1007/s10592-008-9651-9

Xiang XY, Zhang ZX, Wang ZG, Zhang XP, et al. (2015). Transcriptome sequencing and development of EST-SSR markers in Pinus dabeshanensis, an endangered conifer endemic to China. Mol. Breed. 35: 158. http://dx.doi. org/10.1007/s11032-015-0351-0

Yun YE, Yu JN, Nam GH, Ryu SA, et al. (2015). Next-generation sequencing identification and characterization of microsatellite markers in Aconitum austrokoreense Koidz., an endemic and endangered medicinal plant of Korea. Genet. Mol. Res. 14: 4812-4817. http://dx.doi.org/10.4238/2015.May.11.13

Zhang ZY, Cui BB, Mao JF, Pang XM, et al. (2015). Novel polymorphic EST-derived microsatellite markers for the red-listed five needle pine, Pinus dabeshanensis. Conserv. Genet. Resour. 7: 191-192. http://dx.doi.org/10.1007/ s12686-014-0329-y

Zhang ZY, Pang XM, Han JW, Wang Y, et al. (2013). Conservation genetics of Annamocarya sinensis (Dode) Leroy, an endangered endemic species. Genet. Mol. Res. 12: 3965-3974. http://dx.doi.org/10.4238/2013.March.11.9

Zheng WH, Zhuo Y, Liang L, Ding WY, et al. (2015). Conservation and population genetic diversity of Curcuma wenyujin (Zingiberaceae), a multifunctional medicinal herb. Genet. Mol. Res. 14: 10422-10432. http://dx.doi. org/10.4238/2015.September.8.3

Genetics and Molecular Research 15 (2): gmr.15027937

CFUNPEC-RP www.funpecrp.com.br 